\title{
Relation of measures of asthma severity and response to treatment to outcome in acute severe asthma
}

\author{
C T Bolliger, P R Fourie, D Kotze, J R Joubert
}

\begin{abstract}
Background It would be helpful if patients with asthma who require admission to hospital for an acute attack could be identified.
\end{abstract}

Methods The relation between the severity of an attack of asthma as determined by admission assessment and the eventual outcome was studied in 52 asthmatic patients aged 14 to 44 years and admitted to an asthma emergency room. The patient's history, including medication and previous admissions to hospital, was recorded and a clinical assessment, including a full inspiratory and expiratory flow-volume loop, was performed on four occasions: on admission, at two hours and at 12-18 hours after the start of a standardised treatment, and two weeks later on an outpatient basis. Patients who were discharged and who had an uneventful follow up at the two week assessment were defined as good responders. Patients who had to be admitted to hospital after 12 to 18 hours or were readmitted during the two weeks, or both, were defined as poor responders.

Results Thirty eight patients were good responders and 14 were poor responders (seven admitted at 12 to 18 hours, seven returned to hospital). All four patients with a raised arterial carbon dioxide tension $\left(\mathrm{PaCO}_{2}\right)(\geqslant 6 \mathrm{kPa})$ and the three with cyanosis were in the poor responder group, and this group had lower peak expiratory flow (PEF) values (21\% v 30\% predicted) on admission. There was, however, considerable overlap in PEF between the two groups and no clinical measure was able to distinguish between the good and the poor responders reliably. Poor responders had a history of more chronic systemic steroid administration, regular use of inhaled $\beta$ agonists, and asthma related hospital admissions. Nearly all the subjects showing a good response to standardised treatment had a PEF $>75 \%$ predicted and an FEV $>65 \%$ predicted 12 to 18 hours after the start of treatment.

Conclusion Prediction of outcome at admission was not possible in individual patients. A history of poor long term control of asthma, a PEF $<30 \%$ of predicted, a $\mathrm{PaCO}_{2} \geqslant 6 \mathrm{kPa}$, the presence of cyanosis, and lack of early response to treatment indicated a group of asthmatic patients who are less likely to respond to conventional emergency treatment over a short period.

(Thorax 1992;47:943-947)

Early recognition and admission of patients at high risk during an acute attack of asthma should reduce mortality. It is difficult to determine which patients require admission to hospital at the time of presentation in the asthma emergency room. Various studies have identified features associated with a slow recovery, such as poor long term control of asthma, a prolonged attack before hospital admission, and use of maintenance oral corticosteroids. ${ }^{12}$ A poor response to treatment as determined by sequential peak flow readings and measurement of forced expiratory volume in one second $\left(\mathrm{FEV}_{1}\right)$ has been associated with the need for hospital admission of patients with a severe attack of asthma. ${ }^{34}$ Kelsen and coworkers found important residual obstruction at discharge (mean $\mathrm{FEV}_{1} 57 \%$ predicted) in asthmatic patients treated in the emergency room, and a lower $\mathrm{FEV}_{1}$ value in the $26 \%$ of patients who relapsed within 10 days. ${ }^{3}$ Woolcock and coworkers found that a reduction in functional residual capacity could occur during recovery without any increase in $\mathrm{FEV}_{1} .^{5}$ Fischl and coworkers developed a predictive index on asthmatic patients with acute severe obstruction at the time of admission that included objective observations such as pulsus paradoxus, pulse and respiratory rates, and peak flow rate and subjective measures such as the degree of dyspnoea, wheezing, and accessory muscle use. ${ }^{6}$ When looked at prospectively, however, by Rose et.al ${ }^{7}$ and Centor et $a l^{8}{ }^{8}$ the index was found not to be of value.

In a further attempt to predict the speed of recovery from acute severe asthma we studied patients on admission to the emergency asthma room. Details of their history were combined with observations recorded on admission. The response to treatment at predetermined times during the admission period of 12 to 18 hours was related to the need for admission and the relapse rate during the two weeks after discharge.

\section{Methods}

Consecutive patients from 12 to 45 years of age who presented at the emergency asthma room 
Table 1 Treatment protocol

\begin{tabular}{ll}
\hline Fenoterol & $\begin{array}{l}5 \mathrm{ml} 0.02 \% \text { solution, four hourly by face mask nebulisation. } \\
\text { Oxygen }\end{array}$ \\
$\begin{array}{l}40 \% \text { by mask, whenever patient not on fenoteral nebuliser. } \\
\text { Aminophylline }\end{array}$ & $\begin{array}{c}\text { Intravenous } 5 \mathrm{mg} / \mathrm{kg} \text { loading dose for patients not on theophylline } \\
\text { treatment on admission. }\end{array}$ \\
$\begin{array}{l}250 \mathrm{mg} \text { in } 200 \mathrm{ml} 0.9 \% \text { saline given by continuous infusion every six } \\
\text { hours for all patients. }\end{array}$ \\
Pydrocortisone $\quad \begin{array}{l}\text { Intravenous } 200 \mathrm{mg} \text { four hourly, three administrations in total. } \\
30 \mathrm{mg} \text { orally daily } \times \text { three days; }\end{array}$ \\
$\begin{array}{l}\text { then } 20 \mathrm{mg} \text { orally daily } \times \text { three days; } \\
\text { then } 10 \mathrm{mg} \text { orally daily } \times \text { three days. }\end{array}$ \\
$\begin{array}{l}\text { Discontinue for patients not previously on steroids. } \\
10 \text { mg maintenance dose a day for patients on steroid treatment } \\
\text { before admission. }\end{array}$
\end{tabular}

of the allergy clinic, Department of Internal Medicine, Tygerberg Hospital, with severe airways obstruction were eligible for entry into the study. Fifty two patients who fulfilled the criteria for asthma proposed by the American Thoracic Society (ATS) entered the study. ${ }^{9}$ Patients with chronic obstructive pulmonary disease as defined by the ATS were excluded. All patients were of mixed race (brown) or black and belonged to a third world socioeconomic group. On admission (time point 1) all patients were assessed by a house officer and the project leader (CTB). A short history on standardised forms was compiled, including the duration, severity, and possible trigger mechanisms of the present attack; current medication, including long term oral steroids or regular inhaled $\beta$ agonist treatment, or both; and smoking habits. Venous blood was taken for a full blood count and blood chemistry and arterial blood for gas analysis with the patient breathing room air. Height, weight, and temperature were recorded. The physical examination in a sitting position included determination of pulse rate, blood pressure and pulsus paradoxus, dyspnoea, wheeze, accessory muscle use, and central cyanosis. Pulsus paradoxus was judged to be present when a value of 18 $\mathrm{mm} \mathrm{Hg}$ or more was measured. The three subjective factors-dyspnoea (the patient's own assessment), accessory muscle use defined as visible and palpable contraction of the sternocleidomastoid muscles, and wheezing (inspiratory or expiratory rhonchi)-were graded in four categories (absent, mild, moderate, and severe).

An electronic pneumotachograph (ELF SA, flow integration by Epson microcomputer) was used to obtain expiratory and inspiratory flow/ volume curves. The best of three curves was chosen. Peak expiratory flow rate (PEF), peak inspiratory flow rate (PIF), forced vital capacity (FVC), forced inspiratory vital capacity (FIVC), forced expiratory volume in one second $\left(\mathrm{FEV}_{1}\right)$, and $\mathrm{FEV}_{1} / \mathrm{FVC}$ ratios were determined.

Patients were then started on treatment according to a standardised protocol (table 1). Physical examination (as already described) and spirometry were repeated after two hours of treatment (time point 2) and after 12 to 18 hours of treatment (time point 3 ) supervised by the project leader. Patients were assessed at time point 3 for admission or discharge by an independent physician who acted on clinical judgement alone without knowledge of the data on lung function. The span of six hours for the third evaluation was because patients were discharged at a fixed time in the morning after their admission. Blood gases were reanalysed at time point 3 if the arterial carbon dioxide tension $\left(\mathrm{PaCO}_{2}\right)$ was raised in the first sample or if the clinical course indicated a need for blood gas remeasurement. Two weeks later (time point 4) patients were assessed in the outpatient department by the project leader. Special attention was given to the degree of dyspnoea and self reported drug compliance since time point 3. No patient was lost to follow up.

Patients designated as good responders were those successfully discharged from the emergency room at time point 3 who did not require a visit to a hospital's emergency department or an unscheduled visit to a private physician's office up to the outpatient visit at time point 4 . Patients who were admitted to hospital at time point 3 or had to be readmitted within two weeks after discharge, or both, were designated poor responders. The decision 'to readmit a patient after discharge was made by an independent physician who did not participate in the emergency asthma service. The patients' history was reassessed retrospectively on completion of the study from hospital records and private practitioners' files for the number of admissions to hospital, prescriptions for daily oral steroid medication of at least $5 \mathrm{mg}$ of prednisone or at least two puffs twice daily of an inhaled $\beta$ agonist (fenoterol or salbutamol) for at least nine months during the year preceding the current attack, drug compliance, and smoking habit. These data complemented the records that were obtained during the acute stage of the disease.

The study had been approved by the University of Stellenbosch Faculty of Medicine ethics committee; all patients gave informed consent.

\section{DATA ANALYSIS}

Data from good responders and poor responders were compared. The categorical clinical variables (dyspnoea, accessory muscle use, wheeze, and cyanosis) and the historical variables (number of hospital admissions, oral steroid treatment, and regular use of inhaled $\beta$ agonist) were analysed by the $\chi^{2}$ test. Dyspnoea, accessory muscle use, and wheezing were weighted in a dichotomous way as absent to mild or moderate to severe. The continuous variables were analysed by Mann-Whitney U test owing to the non-parametric distribution of the data points. $p$ values of $<0.05$ were accepted as significant. Both groups were assessed by Fischl's predictor index ${ }^{6}$ on admission.

\section{Results}

All 52 patients ( 35 women, 17 men) who entered the study completed all four assessments; 38 were in the good responder group and 14 were in the poor responder group. The mean (SD) age was $28.0(8.4)$ years, range 14 43 , in the good responder group; and $29 \cdot 7(8 \cdot 7)$ 
Table 2 Clinical measures showing differences between good responders and poor responders on hospital admission

\begin{tabular}{|c|c|c|c|c|c|}
\hline \multirow[b]{2}{*}{$\begin{array}{l}\text { PEF }(1 / \mathrm{min})^{\star} \\
\% \text { Predicted }\end{array}$} & \multicolumn{2}{|c|}{$\begin{array}{l}\text { Good responders } \\
(n=38)\end{array}$} & \multicolumn{2}{|c|}{$\begin{array}{l}\text { Poor responders } \\
(n=14)\end{array}$} & \multirow{2}{*}{$\frac{p}{\text { Value }}$} \\
\hline & $\begin{array}{r}112 \\
30\end{array}$ & $(66-162)$ & $\begin{array}{l}60 \\
21\end{array}$ & $(39 \cdot 6-86)$ & \\
\hline Cyanosis & 0 & & 3 & $(21 \%)$ & $<0.01$ \\
\hline $\mathrm{PaCO}_{2} \geqslant 6 \mathrm{kPa}$ & 0 & & 4 & $(29 \%)$ & $<0.01$ \\
\hline Maintenance oral steroid treatment & 7 & $(18 \%)$ & 7 & $(50 \%)$ & $<0.05$ \\
\hline $\begin{array}{l}\text { Regular inhaled } \beta \text { agonist treatment } \\
\text { Number of hospital admissions }\end{array}$ & 30 & $(79 \%)$ & 13 & $(93 \%)$ & $<0.01$ \\
\hline (previous year) & 1. & & 3 & & $<0.05$ \\
\hline
\end{tabular}

${ }^{\star}$ Merdian values with interquartile range in parentheses; PEF-peak expiratory flow; $\mathrm{PaCO}_{2}$-arterial carbon dioxide tension.

years, range 16-44, in the poor responder group. There were no significant differences for sex, height, weight, and smoking habit between the two groups.

Table 2 shows the results of the clinical and historical variables that differed significantly between the two groups on admission. Of the clinical variables only PEF and the number of patients with central cyanosis differed significantly. The median values of $112 \mathrm{l} / \mathrm{min}$ for the good responder and $60 \mathrm{l} / \mathrm{min}$ for the poor responder group differed significantly although there was considerable overlap in PEF values between the two groups (fig 1). Only three of the 14 poor responders had central cyanosis (median arterial oxygen tension $\left(\mathrm{PaO}_{2}\right) 8.0 \mathrm{kPa}$ ). The group median $\mathrm{PaO}_{2}$ values of $9.4 \mathrm{kPa}$ in the good responders and $8.6 \mathrm{kPa}$ in the poor responders did not differ significantly. In the year before the study the poor responders had had more hospital admissions ( $3.5 v 1.2$ a year; $\mathrm{p}<0.05$ ), more prescriptions for prolonged periods of oral corticosteroids $(7 / 14 v 7 / 38 ; \mathrm{p}<$ 0.05 ) and more prescriptions for regular inhaled $\beta$ agonist therapy (13/14 $v 30 / 38 ; \mathrm{p}<$ $0 \cdot 05)$. Fischl's index was significantly higher in the poor responders $(4.71)$ than in the good responders $(3.45 ; p<0.05)$, but the scores showed more overlap than the PEF values. The $\mathrm{PaCO}_{2}$ on admission did not differ between the two groups $(4.5 \mathrm{kPa}$ in good responders $v 4.8$ $\mathrm{kPa}$ in poor responders). The four patients with an initial $\mathrm{PaCO}_{2}$ of $\geqslant 6 \mathrm{kPa}$ were all in the poor responder group, although repeat blood gas determination showed a normal $\mathrm{PaCO}_{2}$ at 12 to

Figure 1 Peak expiratiory flow rate on admission. Box and whisker plots indicate the median values of $P E F$, $25 \%-75 \%$ interquartile range (box), and the 5th and 95 th percentile (circles). Lower values were recorded in the poor responders $(p=0.005)$. The considerable overlap shown prevents accurate prediction from $P E F$ values for individual subjects for sustained remission.
18 hours. There were significant differences in clinical measures and in measures of lung function (figs 2 and 3 ) at various times after treatment. These included differences in accessory muscle use $(p=0.012)$, pulsus paradoxus $(\mathrm{p}=0.03), \operatorname{PEF}(\mathrm{p}=0.002), \mathrm{FEV}_{1}$ $(\mathrm{p}=0.006)$, PIF $(\mathrm{p}=0.036)$, and FVC $(p=0.015)$ two hours after the start of treatment, and dyspnoea $(\mathrm{p}=0.005)$, wheeze $(\mathrm{p}=0.038)$, PEF $(\mathrm{p}=0.036)$, and $\mathrm{FEV}_{1}$ $(p=0.021)$ after 12 to 18 hours of treatment.

When assessed by an independent physician 12 to 18 hours after admission to the emergency room seven of the 14 poor responders were admitted to hospital. The other seven patients in this group returned to the emergency room before the two week assessment and one was subsequently admitted to hospital. Two patients qualified for the poor responder group on both counts.

The poor responders had clinical evidence and lung function tests two weeks after discharge indicative of persistent airways obstruction. The good responders had sustained the improvement in lung function between discharge and the two week follow up visit.

\section{Discussion}

Our two groups of patients presented with acute severe asthma with a mean $\mathrm{FEV}_{1}$ of 0.71 ( $25 \%$ predicted) in the good responders and 0.551 ( $24 \%$ predicted) in the poor responders. ${ }^{10}$ The initial assessment before treatment identified only two factors that differed significantly between the two groups. The range of PEF showed too much overlap to make it a reliable predictor of resistant asthma-as was found by Fiel and coworkers. ${ }^{\text {" }}$ Cyanosis together with a low $\mathrm{PaO}_{2}(<8 \mathrm{kPa})$ was specific for a slow response, but occurred in only three of the 14 poor responders; this makes it too insensitive for prediction of outcome. As the median $\mathrm{PaO}_{2}$ values did not differ between the groups, this measurement was also a poor discriminator. We were thus unable to find a single factor from the initial evaluation that discriminated reliably between good and poor responders. This agreed with the findings of Fischl et al and Fiel and coworkers. ${ }^{611}$ In the paper by Fischl et $a l^{6} 205$ patients attending a Miami hospital's emergency room for treatment of acute asthma were studied. As no single finding on admission could predict outcome the authors proposed a multifactorial index score that ranged from 0 to 7 and increased with severity of symptoms. They found that a score of $\geqslant 4$ was $95 \%$ accurate in predicting the risk of relapse and $96 \%$ accurate in predicting the need for admission to hospital. Eliakim ${ }^{12}$ was able to confirm Fischl's index in a slightly modified form. The clinical data and tests of lung function suggest that the severity of asthma in our patients was similar to that seen in these studies. When we applied Fischl's index to our patients there was a significant difference between the two groups but it was even less useful than the PEF alone owing to a considerable overlap. By contrast with these two studies we were unable to predict outcome 

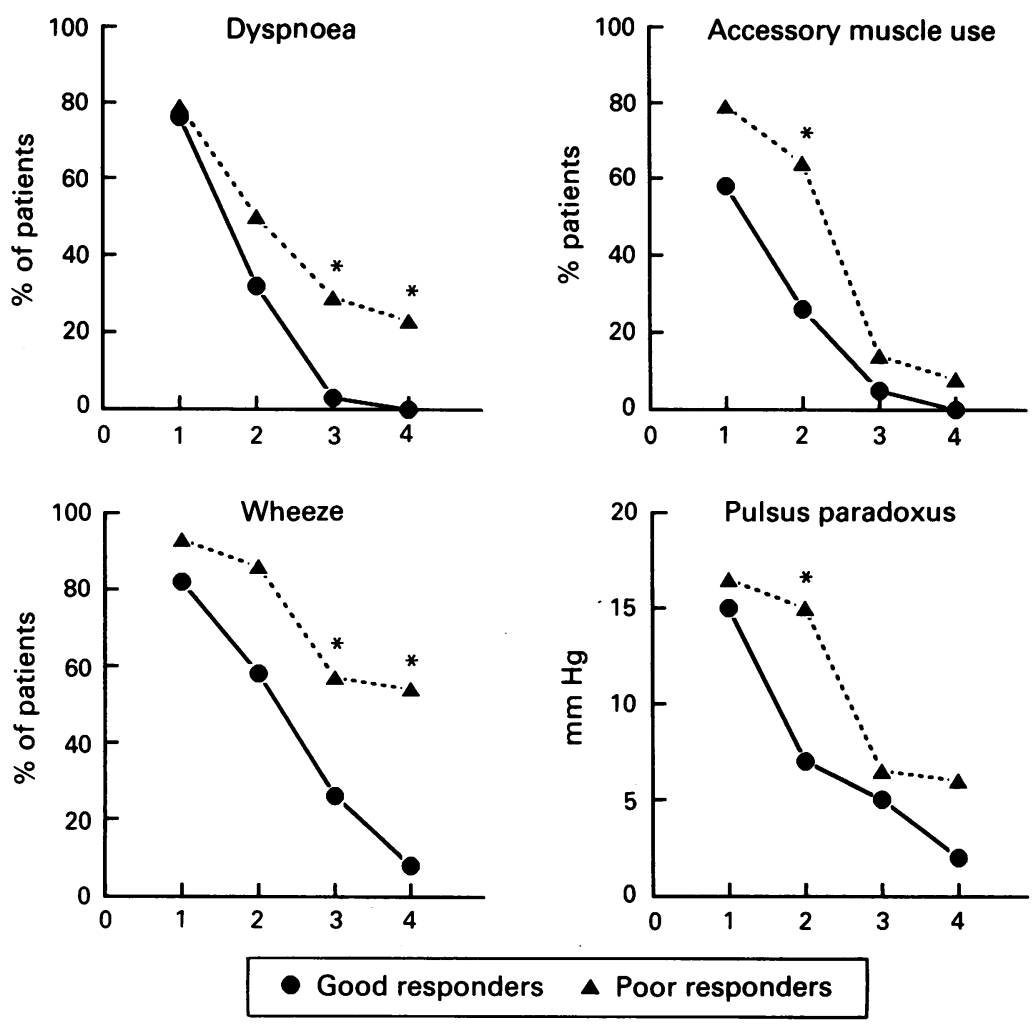

Figure 2 Clinical measures. Change in dyspnoea, accessory muscle use with wheeze, and pulsus paradoxus in asthmatic patients at various times after treatment ( 1 on admission, 2 at two hours, and 3 at 12-18 hours of treatment, 4 at two weeks). The solid line depicts the good responders $(n=38)$, the interrupted line the poor responders $(n=14) .{ }^{\star} p<0.05$ between the two groups.

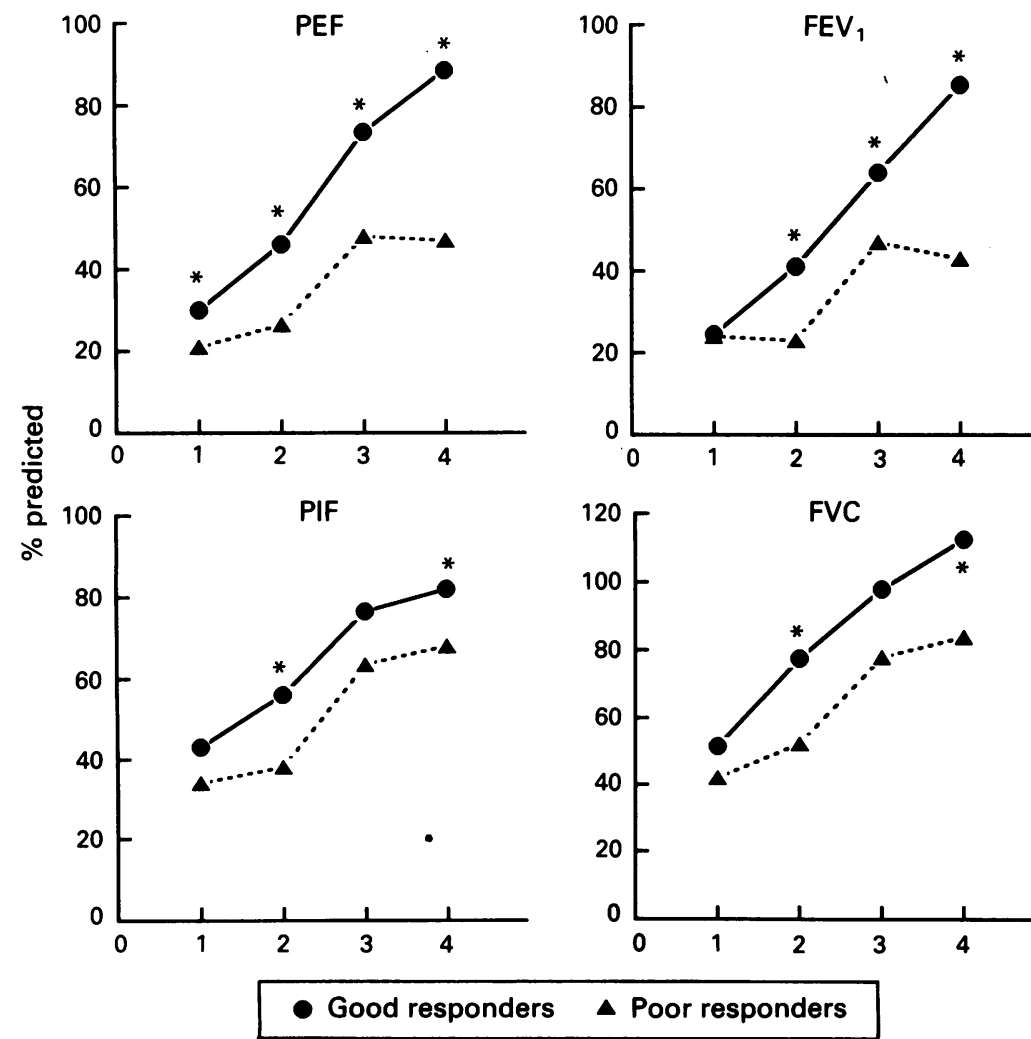

Figure 3 Lung function measures. Change in $P E F, F E V, P I F$, and $F V C$, at various times after treatment (1 on admission, 2 at two hours, and $3=$ at 12-18 hours of treatment, 4 at two weeks. The solid lines depict the good responders $(n=38)$, the interrupted lines the poor responders $(n=14)$. ${ }^{\star} p<0.05$ between the two groups. reliably from our admission with or without a predictor index. These findings are in accordance with most earlier studies that failed to reliably identify high risk patients by measurements of single risk factors ${ }^{3113}$ or by multifactorial predictor indices applied during the hospital stay. ${ }^{78}$

Three factors from the year preceding the current admission (table 2 ) clearly pointed to the need for hospital admission. Jenkins et al found that a longer duration of the acute attack before admission, poor long term control of asthma, and maintenance oral corticosteroids were associated with slow recovery, as were age over 40 years and non-atopic asthma.

In view of the current debate about the role of regular use of inhaled $\beta$ agonists in the increasing morbidity from asthma ${ }^{14-18}$ we checked the prescription records of all patients. This confirmed that almost all (13 of 14 ) poor responders but only 30 of the 38 good responders used inhaled $\beta$ agonists on a regular basis, most in both groups taking salbutamol. The other patients did not use inhaled $\beta$ agonists. Poor recollection by patients made the assessment of preadmission drug compliance difficult and blood concentrations of $\beta$ agonists on admission were not obtained. We cannot tell if regular inhaled use of $\beta$ agonists was an indicator of severity of asthma or whether it could have contributed to the severity of the acute attack.

The faster response to initial treatment in the good responders was best reflected by the course of objective measurements of lung function, in which PEF and $\mathrm{FEV}_{1}$ showed consistent differences between the groups over the treatment period (fig 3). Similar findings were published by Nowak et al..$^{19}$ After two hours of treatment both the PEF and $\mathrm{FEV}_{1}$ had increased to above $40 \%$ predicted in the good responders. These results are similar to those of Fanta et al. ${ }^{20}$ The clinical signs of pulsus paradoxus and accessory muscle use were also useful during the early course, up to two hours from the start of treatment, whereas the degree of dyspnoea and wheeze helped to discriminate the two groups at 12 to 18 hours of treatment only (fig 2). By choosing the median FEV and PEF values of the good responders after 12 to 18 hours of treatment we found discharge values for PEF of $>75 \%$ predicted and for $\mathrm{FEV}_{1}$ of $>65 \%$ predicted, which resulted in a specificity for safe discharge at time point 3 of $93 \%$ for $\mathrm{FEV}_{1}$ and $77 \%$ for PEF. Our recommendations of a PEF $>75 \%$ of predicted are identical with the guidelines of the British Thoracic Society (BTS), ${ }^{21}$ whereas our recommended FE $\mathbb{N}_{1}$ values of $\geqslant 65 \%$ predicted are higher than the $\geqslant 50 \%$ predicted values recommended by Town et al. . $^{22}$ Our values were obtained in a mixed race and black population of southern Africa and after a period of 12 to 18 hours of emergency room treatment, which is longer than that reported in other studies. ${ }^{6220}$ Therefore results cannot be extrapolated to those of other groups.

Evaluation of clinical data and lung function values for our patients two weeks after discharge confirmed persistent airways obstruc- 
tion in the poor responders. The nine patients who were readmitted before time point 4 may have encountered further factors that triggered their asthma at home or in an occupational environment that could not be predicted by the assessment on admission. Compliance with treatment was checked by questionnaire and found to be similar in the two groups. Evaluation of the poor responders' history, response to emergency treatment, and poor discharge course most probably reflected greater asthmatic instability. The poor response to emergency treatment over a period of 12 to 18 hours may, therefore, identify a group of chronically incapacitated asthmatic patients and does not necessarily represent an isolated exceptionally severe attack of asthma.

Although no reliable single factor or index score could be found to predict outcome in our patients, a history of poor long term control of asthma, a PEF of $<30 \%$ predicted, a $\mathrm{PaCO}_{2}$ of $\geqslant 6 \mathrm{kPa}$, and the presence of central cyanosis (and $\mathrm{PaO}_{2}$ of $\leqslant 8 \mathrm{kPa}$ ) were factors associated with hospital admission, or repeat emergency visit after discharge, or both (table 2). $\mathrm{A} \mathrm{PaCO}_{2}$ value increased above normal is generally accepted as evidence of a very severe attack of asthma, ${ }^{23}$ recently re-emphasised by Town $e t$ $a l^{22}$ and by a statement from the British Thoracic Society. ${ }^{21}$ Central cyanosis, a rise of $\mathrm{PaCO}_{2}$, and the presence of pulsus paradoxus were also mentioned as risk factors by Rebuck and Read. ${ }^{24}$

Our results emphasise the value of repeated evaluation of clinical data and lung function to assess the success of treatment. We agree with Banner et al, Kelsen et al, and Corre and Rothstein that the most important factor in predicting the post-discharge course and the need for admission to hospital is an objective determination of an early response to treatment (two to 12 hours)..$^{3425}$

In our study it was not possible in the individual patient to reliably predict on admission the long term response to treatment of an acute severe asthmatic attack. A PEF of $<30 \%$ predicted, a $\mathrm{PaCO}_{2}$ value of $\geqslant 6 \mathrm{kPa}$, the presence of cyanosis, and a history of poor long term control of asthma (recurrent hospital admissions, maintenance steroid medication, and regular use of inhaled $\beta$ agonists), however, are features that point to patients with chronically incapacitating asthma and should alert the attending physician to the need for admission. Patients discharged successfully had an emergency room discharge $\mathrm{FEV}_{1}$ of $>65 \%$ predicted and PEF values $>75 \%$ predicted. These findings in a third world socioeconomic group in southern Africa are in accordance with most published reports from other parts of the world.

1 Williams MH Jr. Life-threatening asthma. Arch Intern Med 1980;140:1604-5.

2 Jenkins PF, Benfield GFA, Smith AP. Predicting recovery from acute severe asthma. Thorax 1981;36:835-41.

3 Kelsen SG, Kelsen DP, Fleeger BF, Jones RC, Todman T. Emergency room assessment and treatment of patients with acute asthma. Am J Med 1978;64:622-8.

4 Banner AS, Shah RS, Addington WW. Rapid prediction of need for hospitalization in acute asthma. JAMA 1976; 235:1337-8.

5 Woolcock AJ, Read J. Improvement in bronchial asthma not reflected in forced expiratory volume. Lancet 1965;ii: 1323-5.

6 Fischl MA, Pitchenik A, Gardner LB. An index predicting relapse and need for hospitalization in patients with acute bronchial asthma. $N$ Engl J Med 1981;305:783-9.

7 Rose CC, Murphy JG, Schwartz JS. Performance of an index predicting the response of patients with acute bronchial asthma to intensive emergency department treatment. N Engl J Med 1984;310:573-7.

8 Centor RM, Yarbrough B, Wood JP. Inability to predict relapse in acute asthma. $N$ Engl J Med 1984;310:577-9.

9 Chronic bronchitis, asthma and pulmonary emphysema. A statement by the committee on diagnostic standards for nontuberculous respiratory diseases. Am Res Respir Dis 1962;85:762-8.

$10 \mathrm{McFadden}$ ER Jr, Lyons HA. Arterial-blood gas tension in asthma. $N$ Engl J Med 1968;278:1027-32.

11 Fiel SB, Swartz MA, Glanz K, Francis ME. Efficacy of short-term corticosteroid therapy in outpatient treatment of acute bronchial asthma. Am J Med 1983;75:259-62.

12 Eliakim R, Halperin Y, Menczel J. A predictor index for hospitalization for patients with acute asthmatic attack. Isr J Med Sci 1984;20:202-6.

13 Martin TG, Elenbaas RM, Pingleton SH. Failure of peak expiratory flow rate to predict hospital admission in acute asthma. Ann Emerg Med 1982;11:466-70.

14 Evans III R. Recent observations reflecting increases in mortality from asthma. J Allergy Clin Immunol 1987;80 377-9.

15 Burney PGJ. Asthma mortality: England and Wales. J Allergy Clin Immunol 1987;80:379-82.

16 Sears MR, Beaglehole R. Asthma morbidity and mortality: New Zealand. J Allergy Clin Immunol 1987;80:383-8.

17 Sears MR, Taylor DR, Print CG, Lake DC, Li Q, Flannery $\mathrm{EM}$, et al. Regular inhaled beta-agonist treatment in bronchial asthma. Lancet 1990;336:1391-6.

18 Spitzer WO, Suissa S, Ernst P, Horwik RI, Habbick B, Cockcroft $\mathrm{D}$, et al. The use of $\beta$-agonists and the risk of death and near death from asthma. $N$ Engl $J$ Med death and near

19 Nowak RM, Pensler MI, Sarkar DD, Anderson JA, Kvale PA, Ortiz AE, et al. Comparison of peak expiratory flow and $F E V_{1}$ admission criteria for acute bronchial asthma. Ann Emerg Med 1982;11:64-9.

20 Fanta $\mathrm{CH}$, Rossing TH, McFadden ER. Emergency room treatment of asthma. Am J Med 1982;72:416-22.

21 British Thoracic Society. Guidelines for management of asthma in adults: II-acute severe asthma. $B M J 1990 ; 301$. asthma in

22 Town I, Kwong T, Holst P, Beasley R. Use of a management plan for treating asthma in an emergency department. Thorax 1990;45:702-6.

23 Wood DW, Downes JJ, Lecks HI. A clinical scoring system for the diagnosis of respiratory failure. Am J Dis Child 1972;124:227-8.

24 Rebuck AS, Read J. Assessment and management of severe asthma. Am J Med 1971;51:788-98.

25 Corre KA, Rothstein RJ. Assessing severity of adult asthma and need for hospitalization. Ann Emerg Med 1985;14: 103-9. 